\title{
Nas entrelinhas do protagonismo jovem: a vivência da produção audiovisual em comunidades rurais de Frederico Westphalen e região
}

\section{Cláudia Herte de Moraes}

Universidade Federal de Santa Maria | Brasil

chmoraes@gmail.com

\section{Janaína Gomes}

Universidade Federal de Santa Maria | Brasil jgomesfw@gmail.com

\section{Resumo}

O projeto Vídeo Entre-Linhas: formação de jovens realizadores em Frederico Westphalen e região é realizado nas chamadas Linhas, que são localidades rurais. 0 principal público é o de jovens que participam de oficinas de audiovisual, ministradas por estudantes de Comunicação da UFSM. Ao final, produzem vídeos que são difundidos nas comunidades. 0 objetivo é capacitar os jovens para a produção da cultura audiovisual e para a sua leitura crítica. Como resultados, apontam-se o valor da atividade extensionista em regiões periféricas; a inclusão social e tecnológica de jovens; o envolvimento comunitário; e a melhor formação de comunicadores, comprometidos com a transformação social.

\section{Palavras-chave}

Cultura audiovisual; Juventude rural; Inclusão tecnológica. 


\section{Bases para o compromisso extensionista}

O Plano Nacional de Extensão Universitária (BRASIL, 1999), com o intuito de estabelecer diretrizes para o período de 2011 a 2020, tem como principal desafio incorporar a atividade extensionista aos currículos universitários. A importância dessa ação compactua para a valorização da atividade extensionista na, até então, utópica indissociação do ensino, pesquisa e extensão. Da mesma forma, permite o engajamento entre universidade e sociedade para a promoção do desenvolvimento social a partir do fomento em áreas estratégicas, bem como na difusão do conhecimento produzido nas ações universitárias.

Essa construção vem evoluindo desde 1999 (BRASIL, 1999; FORPROEXT, 2001), quando os vínculos com a sociedade vêm sendo explicitados, da mesma forma, que esclarecida a inserção das ações universitárias e a busca de acompanhamento e avaliação para que metas sejam alcançadas. Isso, para que cada vez mais, alunos possam comprometer-se com o desenvolvimento regional, contando com o auxílio de um orientador e tendo sua colaboração garantida por objetivos bem estabelecidos e metodologias de avaliação cada vez mais claras.

Nesse contexto, o Projeto Pedagógico do Curso de Comunicação Social - habilitação em Jornalismo da Universidade Federal de Santa Maria, no campus de Frederico Westphalen, salienta a necessidade de flexibilização da formação acadêmica. Um dos mecanismos para fazer isso é a atividade extensionista, que leva os estudantes a buscarem, também, outros pontos de vista na análise e reflexão da realidade que lhes cerca. Assim, o projeto "Vídeo Entre-Linhas: formação de jovens realizadores no interior de Frederico Westphalen e região" colabora com essa visão no âmbito das atividades extensionistas da UFSM, pois é indispensável que a consciência social do jornalista esteja à flor da pele, e esse exercício é constante quando há o deslocamento desses estudantes para uma vivência em grupos de jovens e nos ambientes rurais. Desde 2008, a área de atuação do referido projeto é a Cultura (FORPROEXT, 1998), pois, desde a primeira edição, tem colaborado com o desenvolvimento cultural dos agentes sociais envolvidos e, da mesma forma, com a construção de uma memória social do município e região onde atua.

O objetivo geral do projeto é capacitar jovens do município de Frederico Westphalen e região para a produção audiovisual, levando em consideração que a cultura é o lugar da experiência, da experimentação e do protagonismo social. Dessa forma, esse objetivo se organiza em função de uma meta que visa à ampliação do processo de manifestação cultural de jovens da zona rural, por meio de atividades durante seis meses em cada oficina, compreendendo o estudo de técnicas audiovisuais e a interação com estudantes universitários, na produção, edição e difusão de vídeos de temática livre e de escolha dos grupos participantes. 
Nas entrelinhas do protagonismo jovem

0 projeto consiste em realizar oficinas com jovens entre 11 e 18 anos, preferencialmente nos espaços da própria comunidade, tais como paróquias e escolas rurais. As oficinas têm a duração de 30 horas em cada localidade. Como resultado das oficinas, cada grupo produz um documentário que é discutido e organizado de acordo com os interesses dos adolescentes. Os vídeos finalizados fazem parte de uma Mostra Itinerante que percorre todos os locais participantes e também outros espaços culturais da cidade.

\section{Metodologia comunitária}

O projeto Vídeo Entre-Linhas se estrutura em oficinas com caráter teórico-prático. A jornada de formação é de 30 horas, dividida em seis encontros de cinco horas. A cada encontro, algumas metas são estabelecidas e cumpridas ao longo do convívio entre alunos e população atendida. Nos municípios de Frederico Westphalen, Taquaruçu do Sul e Caiçara, o projeto contou com o apoio das Secretarias de Educação para transporte dos alunos da UFSM até os locais de treinamento, bem como até os locais definidos pelos oficineiros para captação de imagens.

O formato do material audiovisual produzido é o documentário, que trabalha com conteúdo de não ficção, justamente para que forneça um conteúdo ligado a temáticas que constituem a memória social e regional da população atendida. A duração é de, no máximo, 15 minutos, tendo em vista que facilita a veiculação em festivais de cinema universitários.

Os conteúdos abordados nas oficinas são: a) definições sobre comunicação e linguagem audiovisual; b) história do Cinema e formatos de filmes (ficção e não ficção); c) técnicas para a execução do documentário: narrativas, personagens, planos, cortes, etc. As aulas foram elaboradas de forma colaborativa e divididas entre conteúdo teórico, exercício, elaboração de roteiro e execução das filmagens.

Em função da especificidade técnica e de dificuldades tecnológicas, a única etapa que é feita fora da programação do projeto é a edição de imagens, executada pelos monitores, tendo como ponto de partida o roteiro dos filmes executado, exclusivamente, pelos oficineiros. 0 conteúdo final é aprovado pelos participantes.

\section{Atividades desenvolvidas}

O projeto Vídeo Entre-Linhas tem dois níveis de treinamento. O primeiro envolve a seleção e a formação dos alunos, monitores e envolvidos na formação dos jovens realizadores. Essa etapa envolveu a colaboração entre os alunos dos cursos de Jornalismo e Relações Públicas, que, conjuntamente, elaboraram o material didático. Fundamentalmente, o que pautou a troca de 
Nas entrelinhas do protagonismo jovem

conhecimento foi uma apostila que serviu como roteiro para os encontros.

Ao mesmo tempo, por se tratar de um aspecto formativo para os estudantes de graduação participantes, o projeto se propõe a produzir artigos de Iniciação Científica, avaliando a experiência. Com isso, busca colaborar para a formação complementar e integral do jornalista em seu percurso universitário, para que ele perceba a sua função social, entenda as dinâmicas sociais e o papel da cultura e da identidade nesse processo. A geração de pesquisas associadas tem o propósito de produzir aprofundamento teórico e prático na área da Comunicação.

Com a divulgação das ações para a comunidade, por meio da imprensa local, de sites e das mostras realizadas, o projeto traz maior acesso das comunidades aos meios audiovisuais e à difusão da cultura local. As mostras de vídeos são itinerantes, percorrendo as localidades rurais, e outros espaços da cidade. As imagens do projeto, com fotografias captadas pelos monitores e participantes das oficinas, também fazem parte de uma exposição.

Ao lado disso, o projeto se associa a outras atividades culturais, em parcerias realizadas com Organizações Não Governamentais (ONGs) e entidades que trabalham com crianças e adolescentes e que atuam na área cultural, obtendo visibilidade pública e buscando colaborar na constituição de futuras políticas públicas.

No encerramento de cada ano, são realizados debates com todos os envolvidos, professores, monitores, comunidade e jovens, por entendermos que a transformação social, na área da recepção crítica e ativa dos meios de comunicação, é um tema importante para as comunidades.

As oficinas de audiovisual promovidas, a cada edição, objetivam dar acesso às novas tecnologias e incluir socialmente jovens de realidades sociais menos favorecidas, que vivem na zona rural da cidade ou em bairros periféricos. Com isso, os participantes também se aproximam do mundo universitário, ao mesmo tempo em que a cultura local é vivida e revista pelos produtos audiovisuais produzidos.

\section{Público e resultados obtidos}

O projeto atendeu a 13 comunidades durante essa trajetória. Em 2008, ocorreu na Linha São Cristóvão, Linha Pedras Brancas e Linha Castelinho, todas em Frederico Westphalen (FW). Em 2009, atendeu o Núcleo Habitacional São Francisco de Paula; Linha Alto Alegre; Linha São José e Distrito Osvaldo Cruz, nesse mesmo município. Em 2014, foi realizado na Linha 21 de Abril - FW; Linha Fátima - Taquaruçu do Sul; Linha Felin - FW; Linha Faguense - FW; Escola da Família Rural - Faguense - FW; Escola Rui Barbosa - FW; Escola 20 de setembro - Caiçara. 
Nas entrelinhas do protagonismo jovem

Desde 2013,possuiparceria com a Associação de Desenvolvimento Social do Norte do Rio Grande do Sul, representante da CUFA em Frederico Westphalen e região, buscando maior sintonia com entidades que desenvolvem ações de cultura, comunicação e arte para os jovens frederiquenses. 0 projeto tem apoio do poder público municipal, por meio da Prefeitura de Frederico Westphalen, que indica a necessidade de sua continuidade para o fortalecimento da identidade local. Na cidade de Taquaruçu do Sul, a prefeitura também apoia o projeto, além do Conselho Municipal dos Direitos da Criança e do Adolescente (COMDICA).

Pela natureza do projeto extensionista, destacamos, a seguir, os resultados em relação aos três públicos atingidos: o universitário, o público jovem e o comunitário.

\subsection{Público universitário}

Nos relatórios dos monitores, estes afirmam a importância do projeto para seu aprendizado. E, aqui, deixamos claro que esse aspecto é muito mais em função de uma aprendizagem de sensibilidade social, de sentido humano. Isso sem esquecer, claro, das experiências na formação técnica, sem a qual as oficinas não teriam sido realizadas com sucesso. A visão de universidade, de curso superior e de formação profissional que os alunos de Jornalismo e Relações Públicas passam a adquirir, com a atuação no projeto em análise, são redimensionadas e passam a ter reflexos sobre outras atividades acadêmicas.

Ao longo do trabalho, os estudantes fizeram pesquisas e leituras visando à sua capacitação para a oferta das oficinas, com treinamentos realizados no campus, com auxílio de professores e técnicos. O projeto gerou comunicações em congressos, com a publicação de resumos e artigos completos em anais no meio digital, o que caracteriza ampla divulgação de seus resultados. Entre os eventos de 2014, damos destaque para o 32ํㅗㄴ Seminário de Extensão Universitária da Região Sul, realizado em Curitiba, e para o V Encontro Nacional da ULEPICC, ocorrido no Rio de Janeiro.

Conforme relato dos estudantes que participaram desses eventos, há uma forma de troca de conhecimentos sobre espaços do Brasil que são, muitas vezes, desconhecidos entre si:

No V Encontro Nacional da ULEPICC (UFRJ - Rio de Janeiro), posso considerar como o evento em que mais tivemos 'choque' de culturas, uma vez que, no GT em que apresentei o projeto, tínhamos apresentadores dos seguintes estados: Ceará, Minas Gerais, Bahia, Rio de Janeiro e São Paulo. Nesse GT, todos os presentes mostraram interesse durante a apresentação, e posteriormente elogiaram o projeto. Também fizeram várias perguntas, inclusive de como era a questão financeira, principalmente quanto à compra de equipamentos (GARZON, 2014). 
Nas entrelinhas do protagonismo jovem

Entre os alunos do curso de Comunicação Social, o impacto científico foi muito importante, pois como um projeto de longo prazo (é realizado desde 2008), se consolida como uma linha de pesquisa em Educomunicação e em Cultura, além da linha de extensão que beneficia os estudantes. A produção científica não foi totalmente finalizada, pois os dados do projeto encontram-se em análise pelo grupo da ação, visto que o período de um ano é pequeno para a maturação dos resultados e publicações associadas às pesquisas.

\subsection{Público jovem}

Considerando os resultados em relação ao público-alvo, ressaltamos que foram atingidos, pois todas as oficinas ofereceram as condições necessárias para que os grupos fizessem seus vídeos de forma satisfatória e no tempo planejado.

A mobilização dos alunos em torno de seus projetos de vídeo foi uma observação importante, demonstrando o quanto a oportunidade de conhecer novas linguagens e equipamentos pode acrescentar perspectivas diferenciadas no âmbito social. Apontamos, aqui, a necessidade de um processo de inclusão social que seja, ao mesmo tempo, uma inclusão tecnológica que permita a reflexão do audiovisual no cotidiano de cada um.

De acordo com as escolhas das temáticas, observamos, ainda, que os jovens participantes estavam ansiosos em "mostrar a sua cara", pois todos os temas eram vinculados à vida em comunidade, ao histórico dos lugares e aos hábitos mais peculiares do interior. A partir disso, podemos indicar a necessidade de incentivo maior à promoção de oportunidades para esses jovens, como a mobilização política vinda da cidadania local (da qual a universidade deve fazer parte), bem como, principalmente, uma política pública de incentivo à uma linha importante na atualidade, qual seja a educação para os meios de comunicação.

Ainda, nesse tópico, fica evidente que, nos ambientes escolares, responsáveis pela maior carga de um possível "contraponto" ao que se vê nas emissões massificadas da grande mídia, ainda, o audiovisual é pouco explorado. Isso denota a falta de intimidade dos próprios professores com a temática. Entre outras concepções, podem-se visualizar projetos de intensificação do uso do vídeo na escola, sempre acompanhado de um debate crítico do audiovisual, dada a sua fundamental importância na formação das identidades dos adolescentes.

\subsection{Público comunitário}

Quanto à comunidade, temos exemplos de integração com impacto positivo, com a 
Nas entrelinhas do protagonismo jovem

participação do projeto em eventos de caráter comunitário. Entre estes, a participação na Feira do Livro, na cidade de Frederico Westphalen, em 2014, com um público médio de 800 pessoas e com repercussão nos veículos de mídia locais e regionais ${ }^{1}$.

O projeto também foi apresentado no evento de Extensão da UFSM "Diálogos com a Extensão", que pretendeu aproximar a comunidade com as ações de extensão da instituição².

Um importante capítulo da divulgação para a comunidade (e da comunidade) ocorreu por meio do $2^{\circ}$ Festival Nacional de Cinema Estudantil (CinEst), em que o vídeo "Os Porongos da Linha Felin" obteve duas premiações, "Melhor documentário" e "Temática Ambiental".3

0 projeto teve, ainda, divulgação nas rádios e jornais locais. Além disso, foram criados um canal no Youtube e um site para a divulgação das ações. ${ }^{4}$

\section{Considerações finais}

A cada edição do projeto Vídeo Entre-Linhas, refletimos sobre seu alcance social e inclusivo. Ao longo dos anos, a ação demonstrou que atinge alguns pontos essenciais (os quais destacamos a seguir), que demonstram a eficiência de projetos de extensão em ambientes nos quais há pouco acesso às manifestações culturais:

a) Manifestações, ao longo das oficinas, de grande expectativa em realizar seus vídeos e em utilizar as novas tecnologias, resultando num baixíssimo índice de evasão, mesmo considerando que os locais de realização das oficinas podiam ter acesso dificultado a alguns alunos.

b) Do ponto de vista do aprendizado dos futuros jornalistas, as oficinas fizeram com que cada um deles desenvolvesse técnicas de expressão oral para poder explicar aos alunos o funcionamento dos equipamentos e técnicas de audiovisual mínimas necessárias para a realização dos vídeos.

c) 0 projeto conseguiu mobilizar teorias de diferentes perspectivas da Comunicação, tanto da área do Audiovisual como da Educomunicação, da Comunicação Comunitária e Rural, entre outras. 0 interesse pela pesquisa passou também a acompanhar o trabalho, como uma possibilidade de registrar e refletir sobre esses aspectos em congressos, seminários e mostras.

d) $\mathrm{Na}$ área cultural mais ampla, em relação à comunidade, o projeto demonstrou capacidade aglutinadora e de inclusão social, aproximando os meios audiovisuais, por meio das mostras, às comunidades próximas dos alunos das oficinas.

e) A organização do acervo do projeto, que fica à disposição, provavelmente impulsionará outras atividades comunitárias na área, sendo um importante momento de 
Nas entrelinhas do protagonismo jovem

difusão da produção de extensão universitária.

f) A partir do projeto, já estão em tratativas novas abordagens e o estudo de metodologias junto a instituições privadas e públicas, tais como empresas, escolas e prefeituras.

Pelos aspectos descritos acima, acreditamos que os resultados finais do Projeto Vídeo Entre-Linhas foram positivos, cumprindo com seus objetivos e metas. No entendimento da equipe, inclusive, superamos alguns obstáculos, como o difícil acesso aos locais das oficinas e a falta de estrutura destas. A superação foi importante e marcou com ainda mais entusiasmo a conquista dos vídeos produzidos, bem como incrementou a emoção de mostrá-los aos familiares e amigos. Essas cenas ficarão na mente e nos corações dos jovens participantes, tanto das oficinas quanto dos universitários.

Um elemento importante foi verificar que os jovens que participaram, apesar de estarem à margem de processos da utilização de mídias em geral no seu cotidiano, ou na assistência a filmes além dos que são passados na TV aberta, conhecem um pouco da linguagem audiovisual. E, mais ainda, sabem o que lhes falta, no sentido da expressão cultural e na busca desta comunicação. Eles conseguem fazer a crítica à produção cultural hegemônica.

A metodologia aplicada nas oficinas partiu exatamente dessa ideia de que ninguém, mesmo jovem e morador do interior, é uma tábua rasa em matéria de cultura audiovisual. Os monitores estabeleceram as oficinas na busca de aprimorar alguns elementos e na busca da expressão do cotidiano, o que contribuiu para a formação da identidade dos jovens.

Um aspecto de extrema importância foi que muitos jovens que participaram das oficinas passaram a projetar-se nos jovens universitários, numa perspectiva de crescimento social e intelectual. Por outro lado, os universitários integraram-se a outras realidades que, na maioria das vezes, não estão contempladas na sua vivência cotidiana. Aprender a aprender com o outro é, sem dúvida, uma grande contribuição aos acadêmicos e aos jovens participantes.

Observamos que os estudantes universitários acabaram saindo de uma posição de "professores", inicialmente estabelecida, para outra, mais interessante, que foi a de "aprendentes". Tanto para os jovens das Linhas atendidas quanto para os universitários da "cidade", o projeto foi um grande elemento de aprendizagem comunitária e social.

Do ponto de vista de uma difusão de trabalho comunitário, a finalização e retorno à comunidade pelas mostras realizadas podem ser considerados o ponto alto, visto que muitos que "apareceram" no filme estavam presentes, além dos jovens que construíram os vídeos. A emoção em se ver, em ver sua comunidade retratada num documento audiovisual (embora nem todos os vídeos tenham sido documentários), obteve grande ênfase. 
Nas entrelinhas do protagonismo jovem

O projeto tem potencial de continuidade e possibilidade de integrar outras ações de políticas públicas nas áreas da Educação, como, por exemplo, o projeto Mais Educação, levando as oficinas para as escolas de ensino fundamental e médio e contribuindo para a implantação das escolas de tempo integral na região.

Podemos apontar que, entre os desafios, está o de estabelecer novas metodologias. Conforme relatado no item anterior, a busca pelo diálogo entre universidade e universitários, de um lado, e jovens e comunidade de outro, foi um projeto de todos. Porém, é necessário avançar e fazer desse processo um elo ainda mais participativo e menos reativo.

Outro ponto a destacar é a falta de estrutura de algumas escolas, em que sequer o equipamento de vídeo funciona. Além de prejudicar a realização de projetos semelhantes, também não se pode imaginar que o trabalho de assistência ao audiovisual terá continuidade.

Para a realização das oficinas, buscaram-se soluções cooperativas, com empréstimo de materiais, mostrando o lado da superação dos obstáculos. Sobressaiu a ideia de que é possível, mesmo com material escasso, realizar vídeos com a comunidade e integrá-los no sentido da cidadania e da inclusão social.

O limite social do pouco conhecimento audiovisual é ilustrativo para demonstrar a validade das ações extensionistas e a possibilidade de que o audiovisual passe a ser visto como uma necessidade da escola, mais que um desejo de alunos e professores.

É objetivo dar continuidade ao projeto, colaborando para que diferentes produções de cinema e vídeo, próprias ou de profissionais, possam ser levadas aos espaços comunitários, onde, hoje ainda, se conhece pouco de cinema, realizando a extensão universitária com responsabilidade social.

\section{Referências}

BRASIL. Ministério da Educação. Plano nacional de extensão. Brasília. 1999.

FORPROEX, Fórum de Pró-Reitores de Extensão das Universidades Públicas Brasileiras e SESu/MEC. Plano Nacional de Extensão Universitária, Edição Atualizada. Brasil, 2001.

FORPROEX, Fórum de Pró-Reitores de Extensão das Universidades Públicas Brasileiras e SESu/MEC. Plano Nacional de Extensão Universitária, Edição Atualizada. Brasil, 2009.

BRASIL. Política Nacional de Extensão Universitária / elaborado pelo Fórum de Pró-Reitores de Extensão das Instituições Públicas de Educação Superior Brasileiras. 74 p. Apresentado no XXVI Encontro Nacional FORPROEX (2009: Rio de Janeiro, RJ) e aprovado no XXXI Encontro Nacional em Manaus, AM.

GARZON, Vandressa. Relatório Final Monitoria. UFSM: Frederico Westphalen, 2014. 
Nas entrelinhas do protagonismo jovem

Definida_a_programacao_da_32a._Feira_do_Livro.fire>. Acesso em: 18 mai. 2015. | Disponível em: $<$ http://www.folhadonoroeste.com.br/site/noticia/2456-programacao-da-32a-feira-do-livro-e-

divulgada>. Acesso em: 18 mai. 2015.210 Disponível em: $<$ http://www.norters.com.br/site/?page=post\&id=21369>. Acesso em: 18 mai. 2015. | Disponível em: $<$ http://www.fredmagazine.com.br/publicacao-4472-Divulgada_programacao_da_Feira_do_Livro.fire>.

Acesso em: 18 mai. 2015.

2 Disponível em: <http://www.fredericowestphalen-rs.com.br/da-universidade-a-comunidade/>. Acesso em: 18 mai. 2015.

3 Disponível em: $<$ http://site.ufsm.br/noticias/exibir/projetos-de-extensao-ganham-premios-em-festivalna> . Acesso em: 18 mai. 2015.

Vídeos disponíveis no Canal do projeto:

<https://www.youtube.com/channel/UCapE6ht6zEVC8Zz1dbZUnrA>. Acesso em: 18 mai. 2015.

Between the lines of the young protagonists: the experience of audiovisual production in rural communities in Frederico Westphalen and region

\begin{abstract}
The project Vídeo Entre-Linhas: formação de jovens realizadores em Frederico Westphalen e região is performed in so-called Linhas (Lines) which are rural locations. The primary audience is young people who participate in audiovisual workshops, taught by communication students at UFSM. In the end, they produce videos that are widespread in the communities. The goal is to train young people for the audiovisual culture production and its critical reading. As the results of the extension activity in peripheral regions; social and technological inclusion of young people; community involvement; and better training of communicators, committed to social transformation.
\end{abstract}

\section{Keywords}

Audiovisual culture; Rural youth; Technological inclusion.
Entre las líneas de los jóvenes protagonistas: la experiencia de la producción audiovisual en las comunidades rurales en Frederico Westphalen y Región

\section{Resumen}

El proyecto Vídeo Entre-Linhas: formação de jovens realizadores em Frederico Westphalen e região se lleva a cabo en las llamadas Linhas (Líneas), que son las localidades rurales. El público principal son los jóvenes que participan en los talleres audiovisuales, impartidos por estudiantes de comunicación de la UFSM. Al final, producen videos que son exhibidos en las comunidades. El objetivo es formar a los jóvenes para la producción de la cultura audiovisual y su lectura crítica. Como resultado destacase el valor de la actividad de extensión en las regiones periféricas; la inclusión social y tecnológica de los jóvenes; la participación de la comunidad; y además califica la formación de los comunicadores, comprometiéndolos con la transformación social.

\section{Palabras clave}

Cultura audiovisual; Juventud rural; Inclusión tecnológica. 
Sobre as autoras:

\section{Cláudia Herte de Moraes}

Jornalista. Mestre em Ciências da Comunicação. Doutora em Comunicação e Informação. Professora no Departamento de Ciências da Comunicação Universidade Federal de Santa Maria (UFSM), Campus Frederico Westphalen. Pesquisadora do Grupo de Pesquisa em Jornalismo Ambiental (CNPq/UFRGS).

\section{Janaína Gomes}

Jornalista. Mestre em Comunicação e Informação. Doutora Agronegócios. Professora no Departamento de Ciências da Comunicação Universidade Federal de Santa Maria (UFSM), Campus Frederico Westphalen. 